\title{
Optimization of the culture medium using the Burman and Box-Behnken experimental designs for an enhanced production of alginate by Azotobacter vinelandii
}

\author{
Abd El-Raheem R. El-Shanshoury ${ }^{1 *}$, El-Refaie Kenawy ${ }^{2}$, Amro A. Amara ${ }^{3,4}$, \\ SaMia F. MOHAMED ${ }^{5}$, Afrah F. Salama ${ }^{6}$, ShimaA KishK ${ }^{6}$ \\ ${ }^{1}$ Bacteriology Research Unit, Microbiology Section, Botany Department, Faculty of Science, Tanta University, Tanta, Egypt \\ ${ }^{2}$ Polymer Research Unit, Chemistry Department, Faculty of Science, Tanta University, Tanta, Egypt \\ ${ }^{3}$ Protein Research Department, Genetic Engineering and Biotechnology Research Institute, \\ City of Scientific Research and Technology Applications, Alexandria, Egypt \\ ${ }^{4}$ Microbiology Division, Pharmaceutical Department, Faculty of Pharmacy at King Saud University (KSU), \\ Riyadh, Kingdom of Saudi Arabia \\ ${ }^{5}$ Pharmacology and Toxicology Unit, Department of Biochemistry, Animal Health Institute, Giza, Egypt \\ ${ }^{6}$ Biochemistry Unit, Chemistry Department, Faculty of Science, Tanta University, Tanta, Egypt
}

\begin{abstract}
Alginates are regarded as high-value biomacromolecules. A pursuit for new bacterial species that can produce novel alginates for various applications in different industries including the pharmaceutical and food industries as well as the field of medicine is still needed. Variations in the molecular weight and sugar composition of alginates depend on the culture medium composition and different physical conditions provided during fermentation. The aim of this study was to obtain a maximum alginate production by the potent Egyptian bacterial strain Azotobacter vinelandii, out of the 30 tested Azotobacter isolates. The composition of the production medium and environmental growth conditions during fermentation were optimized to ensure consistency and to enhance alginate production. Nine variables were optimized using the Plackett-Burman randomization method. Eighteen trials were performed to verify the variables to obtain high alginate production levels. Temperature as well as sucrose and $\mathrm{NaCl}$ concentrations have been found to affect the alginate production by $A$. vinelandii significantly and were therefore chosen for further improvement of the medium using the Box-Behnken design. The Box-Behnken model was optimized mathematically using the Excel solver. The results were analyzed statistically by ANOVA multiple regression analysis and different statistical methods (coefficient, standard error, $t$ statistic, and confidence interval). On using the Plackett-Burman and Box-Behnken designs, the biggest alginate production rates were found to be 3.8 and $4.94 \mathrm{~g} / \mathrm{l} / \mathrm{day}$, respectively. Addition of $00.1 \mathrm{~g} / 1 \mathrm{MgSO}_{4}, 0.01 \mathrm{~g} / 1 \mathrm{FSO} 4$, and $0.001 \mathrm{~g} / 1 \mathrm{NaMoO}_{4}$ to the culture medium further enhanced the alginate production and yielded $5.4 \mathrm{~g} / \mathrm{l} /$ day and $8.5 \mathrm{~g} / \mathrm{l} /$ day. Thus, the obtained alginate was purified using Sephadex G-100 Gel chromatography and compared with a standard by IR correlation. The alginate was found to be composed of $50-70 \%$ carbohydrates and $60-80 \%$ uronic acid. The techniques used in this survey were found useful for improving the production of alginates.
\end{abstract}

Key words: alginate, Azotobacter vinelandii, Box-Behnken, optimization, Plackett-Burman, culture medium

\section{Introduction}

Alginate is a negatively charged polymer, present in viscous solutions in a soluble (in the absence of divalent cations) or in a gel-like (in the presence of divalent or trivalent cations) form. Alginates are exopolysaccharides composed of linear copolymers containing blocks of $(1,4)$-linked $\beta$-D-mannuronate $(\mathrm{M})$ and $\alpha$-L-guluronate $(\mathrm{G})$ residues (Auhim and Hassan, 2013). The blocks are arranged as homogeneous poly-G (GGGGGG) or poly-M (MMMMMM) sections or alternating $\mathrm{M}$ - and G-residues

\footnotetext{
* Corresponding author: Bacteriology Research Unit, Microbiology Section, Botany Department, Faculty of Science, Tanta University, Tanta 31527, Egypt; e-mail: abrabsh@gmail.com
} 
(GMGMGM) in a block in a similar manner. Alginates differ in terms of $\mathrm{M}$ and $\mathrm{G}$ contents as well as compositions of each block, with a common molecular formula $\left(\mathrm{C}_{6} \mathrm{H}_{8} \mathrm{O}_{6}\right)$ and with a molar mass ranging between 10 and $600 \mathrm{kDa}$ (Charles et al., 2012; Szekalska et al., 2016). The extracellular accumulation of alginates serves as a barrier for diffusion of oxygen or heavy metals and/or as a protection against other environmental threats (Segura et al., 2003). It plays an important role in biofilm formation (Thielen et al., 2005) and interacts with $\mathrm{Ca}^{2+}$ to form $\mathrm{Ca}^{+2}$ alginate complexes (Schmid et al., 2008). Although brown seaweeds are the main source for the commercial obtainment of alginates, bacterial biosynthesis constitutes an interesting alternative as it offers the production of alginates with more defined chemical structures and physical properties than those isolated from seaweeds. The valuable properties of bacterial alginates ensure an increasing interest from various industries (Sabra, 1999; Diaz-Barrera and Sot, 2010; Mejia et al., 2010). Alginates produced by bacteria are rich in mannuronic acid (Rehm and Valla, 1997; Sabra, 1999). Those produced by $A$. vinelandii have a high molecular mass of up to 1,350 kDa (Mejia et al., 2010; Diaz-Barrera et al., 2011), although a molecular mass of about $4000 \mathrm{kDa}$ produced by a mutant strain of $A$. vinelandii has also been reported (Pena et al., 2002). Moreover, bacterial strains acetylate alginates, whereas alginates obtained from algae are not acetylated. Both, alginate acetylation and molecular mass affect alginate viscosity and other properties (Pena et al., 2006; Auhim and Hassan, 2013). Various bacteria, especially Pseudomonas and Azotobacterspp. can synthesize alginates; however, alginates from Azotobacter sp. are preferred for technical and medical applications. Strains of $A$. chroococcum can also produce alginates (Cote and Krull, 1988). $A$. vinelandii requires alginates for the encystment process; cysts in their mature form are surrounded by two discrete layers rich in alginates, which enable the sleeping cells to survive long periods of desiccation. Alginates from Azotobacter sp. contain polyguluronates, which form rigid gels in the presence of $\mathrm{Ca}^{2+}$ and are also important in the formation of cysts. Conversely, in the absence of polyguluronates, but in the presence of $\mathrm{Ca}^{2+}$, relatively flexible gels are produced by Pseudomonas aeruginosa (Sherbroock-Cox et al., 1984).

Alginate is a biomaterial that has many applications. They are used in the production of ice creams, frozen custards, creams, and cake mixtures in the food industry and in beer manufacture to enhance the formation of foam (Neidleman, 1991). In biotechnological applications, alginates are used for cell immobilization, and in the production of ethanol by yeast and monoclonal antibodies by hybridoma cells (Crescenzi, 1995). Alginates increase the flocculate aggregation (Dekwer and Hempel, 1999) in water treatment processes (Grasdalen, 1983; Rehm and Valla, 1997; Sabra et al., 2001). They have found many applications in the biomedical and engineering sectors due to their favorable properties, including biocompatibility and ease of gelation. Alginate hydrogels have been particularly attractive in specific sectors such as biomedicals and pharmaceuticals, in particular; in developing controlled drug delivery systems, wound healing, tissue engineering, and the food industry (Remminghorst and Rehm, 2006; Galindo et al., 2007; Yao et al., 2009; Lee and Mooney, 2012; Rinaudo, 2014). Alginates are suitable for use as matrices for three-dimensional tissue cultures, adjuvants of antibiotics, and antiviral agents in cell transplantation in diabetes or neurodegenerative disease treatment (Szekalska et al., 2016).

\section{Materials and methods}

\section{Microorganisms and basal medium}

Soil samples, including cultivated and uncultivated ones, were collected from different localities in Tanta, Gharbia Governorate, Egypt. Thirty isolates belonging to the genus Azotobacter were isolated. The bacterial strains were purified by subculturing on a nitrogen-free medium, as described by Vancura and Mancura (1960). Its composition was as follows (per liter): $20 \mathrm{~g}$ sucrose; $0.65 \mathrm{~g} \mathrm{~K}_{2} \mathrm{HPO}_{4} ; 0.16 \mathrm{~g} \mathrm{KH}_{2} \mathrm{PO}_{4} ; 0.2 \mathrm{~g} \mathrm{NaCl} ; 0.2 \mathrm{~g}$ $\mathrm{MgSO}_{4} \cdot 7 \mathrm{H}_{2} \mathrm{O} ; 2$ g CaCO3; $0.005 \mathrm{~g} \mathrm{NaMoO}_{4} \cdot 2 \mathrm{H}_{2} \mathrm{O}$; $0.005 \mathrm{~g} \mathrm{Fe}_{2}\left(\mathrm{SO}_{4}\right)_{3} ; 0.005 \mathrm{~g} \mathrm{NaBO}_{4}$, and $15 \mathrm{~g}$ Bacto-agar, prepared at a $\mathrm{pH}$ of 7 . Of 30 isolates, five highest $\mathrm{N}$-fixers and alginate producers were selected and characterized. Among the five isolates chosen for further studies, isolate $\mathrm{Az} 5$, the highest alginate producing ability, identified by El-Shanshoury and coworkers (2013) as A. vinelandii was also used in this study.

\section{Alginate production}

Following the composition of the medium used for alginate production: $30 \mathrm{~g} / 1$ sucrose; $2 \mathrm{~g} / 1 \mathrm{NaNO}_{3} ; 1 \mathrm{~g} / 1$ 
Table 1. Morphological characteristics and quantification of alginates produced by selected Azotobacter isolates

\begin{tabular}{|c|c|c|c|c|}
\hline \multirow{2}{*}{$\begin{array}{l}\text { Isolate } \\
\text { code }\end{array}$} & \multicolumn{2}{|c|}{ Morphology of colonies $^{1}$} & \multirow{2}{*}{$\begin{array}{c}\text { Alginate }^{2} \\
{[\mathrm{~g} / \mathrm{l}]}\end{array}$} & \multirow{2}{*}{$\begin{array}{c}\text { Levels } \\
\text { of alginate }\end{array}$} \\
\hline & color & elevation & & \\
\hline $\mathrm{A} z 1$ & brown & raised & 0.60 & low \\
\hline $\mathrm{Az} 2$ & translucent & convex & 1.45 & high \\
\hline $\mathrm{Az} 3$ & translucent & raised & 0.58 & low \\
\hline $\mathrm{Az} 4$ & brown & raised & 0.80 & moderate \\
\hline Az5 & translucent & raised & 1.50 & high \\
\hline
\end{tabular}

${ }^{1}$ All isolates were isolated from soil, the surface of their colonies was smooth and the colony margin was entire; ${ }^{2}$ Alginate produced by the selected Azotobacters in a nitrogen-free liquid medium; ${ }^{3}$ Low producers $(0.58-0.60 \mathrm{~g} / \mathrm{l})$, moderate producers $(0.80 \mathrm{~g} / \mathrm{l})$, and high producers $(1.45-1.50)$

Table 2. Effect of different variables on alginate production rate by $A$. vinelandii utilizing the Plackett-Burman design

\begin{tabular}{|c|c|c|c|c|c|c|c|c|c|c|c|}
\hline \multicolumn{2}{|c|}{$\begin{array}{c}\text { Experiment } \\
\text { no. }\end{array}$} & $X_{1}$ & $X_{2}$ & $X_{3}$ & $X_{4}$ & $X_{5}$ & $X_{6}$ & $X_{7}$ & $X_{8}$ & $X_{9}$ & $\begin{array}{l}\text { Alginate } \\
\text { production rate } \\
\text { [g/l/day] }\end{array}$ \\
\hline$+a$ & 1 & $-1(30)$ & $1(7)$ & $1(30)$ & $1(2)$ & $1(1)$ & $1(0.5)$ & $1(0.5)$ & $1(0.05)$ & $-1(200)$ & 2.7 \\
\hline \multirow{16}{*}{$\begin{array}{l}\text { Plackett- } \\
\text { Burman } \\
\text { experiments }\end{array}$} & 2 & $-1(30)$ & $-1(5)$ & $1(30)$ & $-1(0.1)$ & $1(1)$ & $1(0.5)$ & $1(0.5)$ & $-1(0)$ & $1(250)$ & 0.3 \\
\hline & 3 & $-1(30)$ & $1(7)$ & $-1(5)$ & $1(2)$ & $-1(0)$ & $1(0.5)$ & $1(0.5)$ & $1(0.05)$ & $-1(200)$ & 0.6 \\
\hline & 4 & $1(37)$ & $1(7)$ & $1(30)$ & $1(2)$ & $1(1)$ & $-1(0)$ & $1(0.5)$ & $1(0.05)$ & $1(250)$ & 3.0 \\
\hline & 5 & $1(37)$ & $-1(5)$ & $1(30)$ & $-1(0.1)$ & $1(1)$ & $1(0.5)$ & $-1(0)$ & $1(0.05)$ & $1(250)$ & 2.4 \\
\hline & 6 & $1(37)$ & $-1(5)$ & $-1(5)$ & $1(2)$ & $-1(0)$ & $1(0.5)$ & $1(0.5)$ & $-1(0)$ & $1(250)$ & 0.7 \\
\hline & 7 & $1(37)$ & $-1(5)$ & $-1(5)$ & $1(2)$ & $1(1)$ & $-1(0)$ & $1(0.5)$ & $1(0.05)$ & $-1(200)$ & 1.0 \\
\hline & 8 & $-1(30)$ & $-1(5)$ & $-1(5)$ & $-1(0.1)$ & $1(1)$ & $1(0.5)$ & $-1(0)$ & $1(0.05)$ & $1(250)$ & 0.1 \\
\hline & 9 & $1(37)$ & $1(7)$ & $-1(5)$ & $-1(0.1)$ & $-1(0)$ & $1(0.5)$ & $1(0.5)$ & $-1(0)$ & $1(250)$ & 0.2 \\
\hline & 10 & $1(37)$ & $-1(5)$ & $1(30)$ & $-1(0.1)$ & $-1(0)$ & $-1(0)$ & $1(0.5)$ & $1(0.05)$ & $-1(200)$ & 1.9 \\
\hline & 11 & $-1(30)$ & $-1(5)$ & $-1(5)$ & $-1(0.1)$ & $-1(0)$ & $-1(0)$ & $-1(0)$ & $1(0.05)$ & $1(250)$ & 0.0 \\
\hline & 12 & $-1(30)$ & $1(7)$ & $-1(5)$ & $1(2)$ & $-1(0)$ & $-1(0)$ & $-1(0)$ & $-1(0)$ & $1(250)$ & 0.0 \\
\hline & 13 & $-1(30)$ & $1(7)$ & $1(30)$ & $-1(0.1)$ & $1(1)$ & $-1(0)$ & $-1(0)$ & $-1(0)$ & $-1(200)$ & 3.8 \\
\hline & 14 & $1(37)$ & $1(7)$ & $1(30)$ & $-1(0.1)$ & $-1(0)$ & $1(0.5)$ & $-1(0)$ & $-1(0)$ & $-1(200)$ & 1.3 \\
\hline & 15 & $-1(30)$ & $-1(5)$ & $1(30)$ & $1(2)$ & $-1(0)$ & $-1(0)$ & $1(0.5)$ & $-1(0)$ & $-1(200)$ & 2.4 \\
\hline & 16 & $-1(30)$ & $1(7)$ & $-1(5)$ & $1(2)$ & $1(1)$ & $-1(0)$ & $-1(0)$ & $1(0.05)$ & $-1(200)$ & 2.2 \\
\hline & 17 & $1(37)$ & $1(7)$ & $1(30)$ & $1(2)$ & $1(1)$ & $1(0.5)$ & $-1(0)$ & $-1(0)$ & $1(250)$ & 2.7 \\
\hline$-b$ & 18 & $1(37)$ & $-1(5)$ & $-1(5)$ & $-1(0.1)$ & $-1(0)$ & $-1(0)$ & $-1(0)$ & $-1(0)$ & $-1(200)$ & 1.0 \\
\hline
\end{tabular}

Where: $X_{1}$ - temperature, $X_{2}-\mathrm{pH}, X_{3}$ - sucrose, $X_{4}-\mathrm{NaNO}_{3}, X_{5}-\mathrm{KH}_{2} \mathrm{PO}_{4}, X_{6}-\mathrm{NaCl}, X_{7}-\mathrm{MgSO}_{4}, X_{8}-\mathrm{FeSO}_{4}, X_{9}-$ shaking rate

$\mathrm{KH}_{2} \mathrm{PO}_{4} ; 0.5 \mathrm{~g} / 1 \mathrm{NaCl} ; 0.5 \mathrm{~g} / 1 \mathrm{MgSO}_{4} ; 0.05 \mathrm{~g} / 1 \mathrm{FeSO}_{4}$; $0.005 \mathrm{~g} / 1 \mathrm{NaMoO}_{4} ; 0.06 \mathrm{~g} / 1 \mathrm{CaCl}_{2}$, and $15 \mathrm{~g} / 1$ Bacto-agar. Alginate production was performed in $250 \mathrm{ml}$ Erlenmeyer flasks containing $100 \mathrm{ml}$ alginate production me- dium. The medium composition and the environmental factors were altered during the running of both PlackettBurman and Box-Behnken designs (Plackett and Box, 1946) as described in Tables 1 and 5. 


\section{Medium optimization for alginate production using the Plackett-Burman and Box-Behnken designs}

The Plackett-Burman design (Plackett and Burman, 1946) was used for screening the effect of nine variables, including temperature $\left[X_{1}\right], \mathrm{pH}\left[X_{2}\right]$, sucrose $\left[X_{3}\right]$, $\mathrm{NaNO}_{3}\left[X_{4}\right], \mathrm{KH}_{2} \mathrm{PO}_{4}\left[X_{5}\right], \mathrm{NaCl}\left[X_{6}\right], \mathrm{MgSO}_{4}\left[X_{7}\right], \mathrm{FeSO}_{4}$ $\left[X_{8}\right]$, and shaking rate $\left[X_{9}\right]$. Eighteen experiments were performed for the analysis of nine variables (Table 1). The results of the Plackett-Burman design were applied to the linear multiple regression analysis, using Microsoft Excel 2002, as described by Abdel-Fattah and Olama (2002). From the statistical analysis of the data collected in Table 1 and summarized in Table 2 , the variables with confidence levels $\geq 90 \%$ were considered to be significantly affected by the alginate production rate. Variables with confidence levels between $70 \%$ and $90 \%$ were considered effective (Stowe and Mayer, 1966). The model created for the analysis of the Plackett-Burman experimental design using a multiple regression analysis was based on the First-order model, where $\mathrm{Y}=\beta_{0}+\sum \beta_{i} \cdot X_{i} \cdot Y$ was the predicted response, $\beta_{0}$ was the model constant, and $X_{i}$ indicated the different variables used (Plackett and Burman, 1946). Three most influential variables out of nine were selected (sucrose $\left[X_{1}\right]$, temperature $\left[X_{2}\right]$ and $\left.\mathrm{NaCl}\left[X_{3}\right]\right)$ for further optimization using the BoxBehnken experimental design. The randomization represented three levels: high (+1), medium (0), and low $(-1)$. The variables were: $\left[X_{1}\right] 30,17.5$, and $5 \mathrm{~g} / \mathrm{l} ;\left[X_{2}\right] 37$, 33.5 , and $30^{\circ} \mathrm{C} ;\left[X_{3}\right] 0.5,0.25$, and $0 \mathrm{~g} / \mathrm{l}$. The results obtained from running the Box-Behnken experiment (Table 5) were analyzed by a linear multiple regression analysis. The response surface and counterparts were predicted for each of the 2 responses using Microsoft Excel 2000 and Essential Exp., Version 2.205 software (Steppan et al.,1998). The designed models were applied using the coefficient results of each variable. Of the three variables randomized in the Box-Behnken experiment, the following equation was used:

$$
\begin{aligned}
Y & =\beta_{0}+\beta_{1} X_{1}+\beta_{2} X_{2}+\beta_{3} X_{3}+\beta_{12} X_{1} X_{2}+\beta_{13} X_{1} X_{3} \\
& +\beta_{23} X_{2} X_{3}+\beta_{11} X_{1}^{2}+\beta_{22} X_{2}^{2}+\beta_{33} X_{3}^{2}
\end{aligned}
$$

where $X_{1}, X_{2}$, and $X_{3}$ were independent variables; $\beta_{1}, \beta_{2}$, and $\beta_{3}$ were linear coefficients; $\beta_{12}, \beta_{13}$, and $\beta_{23}$ were cross product coefficients; and $\beta_{11}, \beta_{22}$, and $\beta_{33}$ were the quadratic coefficients. Sucrose $\left[X_{1}\right]$, temperature $\left[X_{2}\right]$, and $\mathrm{NaCl}\left[X_{3}\right]$ were further optimized to calculate the best alginate production rate $(Y)$ using the Microsoft Excel 2002 solver. The $Y$ values determined by the Excel sol-

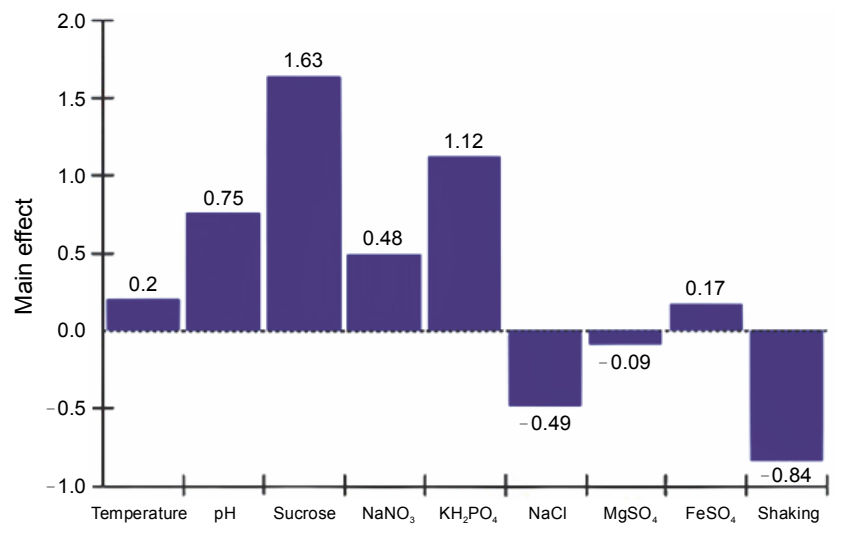

Fig. 1. Effects of environmental conditions and cultural constituents on the rate of alginate production by $A$. vinelandii

ver were experimentally verified using the calculated optimum values of sucrose $\left[X_{1}\right]$, temperature $\left[X_{2}\right]$, and $\mathrm{NaCl}\left[X_{3}\right]$. The accuracy percentage of the model was calculated using the following formula: accuracy of the model $\left.=\left[Y_{\text {experiment }} / Y_{\text {calculated }}\right] \times 100\right]$. To prove the model's accuracy, the variables in the calculated $Y$ were tested experimentally and the alginate production rate ( $Y$ experiment) was determined.

\section{Partial purification and characterization of alginates}

The growth culture of $A$. vinelandii was subjected to vortexing at $560 \mathrm{~g}$ for $3 \mathrm{~min}$ and the cells were separated from the supernatant by centrifugation at $1360 \mathrm{~g}$. Proteins present in the supernatant were separated from alginates by adding $10 \%(\mathrm{w} / \mathrm{v})$ trichloroacetic acid (TCA) (Van den Berg et al., 1995). The precipitated proteins were removed by centrifugation at $605 \mathrm{~g}$ for $30 \mathrm{~min}$. After removing the protein fractions, a clear supernatant was collected and allowed to stand overnight at $4^{\circ} \mathrm{C}$. Next, the alginates were precipitated by adding 3 volumes of cold ethanol. Alginate precipitates were collected by centrifugation at $2840 \mathrm{~g}$ for $30 \mathrm{~min}$ and lyophilized. Alginates were purified using Sephadex G-100 column $(1.5 \times 45 \mathrm{~cm})$ (Pharmacia Fine Chemicals) with a bed volume of approximately $73 \mathrm{ml}$. The column was equilibrated with BioUltra Phosphate buffer solution ( $\mathrm{pH}$ 7.2) composed of $0.044 \mathrm{M} \mathrm{Na}_{2} \mathrm{HPO}_{4}, 0.022 \mathrm{M} \mathrm{NaH}_{2} \mathrm{PO}_{4}$, and the elution was accomplished at a flow rate of 8 drops/ min. Three-milliliter fractions were collected, then the total carbohydrate content, uronic acid level, and the contaminating proteins were determined. A carbazol assay was performed to determine the amount of uronic acid in the purified alginate according to the procedure 
Table 3. Main effect of each variable on alginate production rate by $A$. vinelandii utilizing the Plackett-Burman design

\begin{tabular}{c|l|c|c|c|c}
\hline \multirow{2}{*}{ Code } & \multirow{2}{*}{ Variable $(-1 /+1)$} & \multicolumn{2}{|c|}{ Values } & \multirow{2}{*}{ Unit } & \multirow{2}{*}{ Main effect } \\
\cline { 3 - 4 } & & $\left(\sum+1\right) / n_{(+1)}$ & $\left(\sum-1\right) / n_{(-1)}$ & & \\
\hline $\mathrm{A}$ & Temperature (30/37) & 1.555556 & 1.354444 & ${ }^{\circ} \mathrm{C}$ & 0.201111 \\
\hline $\mathrm{B}$ & $\mathrm{pH}(5 / 7)$ & 1.831852 & 1.078148 & $\mathrm{pH}$ & 0.753704 \\
\hline $\mathrm{C}$ & Sucrose $(5 / 30)$ & 2.272222 & 0.637778 & $\mathrm{~g} / 1$ & 1.634444 \\
\hline $\mathrm{D}$ & $\mathrm{NaNO}_{3}(0.1 / 2)$ & 1.693333 & 1.216667 & $\mathrm{~g} / 1$ & 0.476667 \\
\hline $\mathrm{E}$ & $\mathrm{KH}_{2} \mathrm{PO}_{4}(0 / 1)$ & 2.016667 & 0.893333 & $\mathrm{~g} / 1$ & 1.123333 \\
\hline $\mathrm{F}$ & $\mathrm{NaCl}^{(0 / 0.5)}$ & 1.211481 & 1.698519 & $\mathrm{~g} / 1$ & -0.48704 \\
\hline $\mathrm{G}$ & $\mathrm{MgSO}_{4}(0 / 0.5)$ & 1.409259 & 1.500741 & $\mathrm{~g} / 1$ & -0.09148 \\
\hline $\mathrm{H}$ & $\mathrm{FeSO}_{4}(0 / 0.5)$ & 1.54 & 1.37 & $\mathrm{~g} / 1$ & 0.17 \\
\hline $\mathrm{I}$ & $\mathrm{Shaking} \mathrm{rate}(200 / 250)$ & 1.036667 & 1.873333 & $\mathrm{rpm}$ & -0.83667 \\
\hline
\end{tabular}

Where: -1 (low) and +1 (high); main effect $=\left(\sum+1\right) / n_{(+1)}-\left(\sum-1\right) / n_{(-1)}$

Table 4. Linear multiple regression results of the Plackett-Burman design

\begin{tabular}{l|c|c|c|c|c|c}
\hline \multicolumn{1}{c|}{ Variables } & Coefficient & $\mathrm{SE}$ & $t$-value & $P$-value & $\mathrm{CL}(\%)$ & Rank \\
\hline Intercept & 0.146111 & 0.17572 & 8.31499 & 0.0000 & 100 & \\
\hline $\mathrm{FeSO}_{4}$ & 0.0259903 & 0.204006 & 0.1274 & 0.9018 & 9.82 & 9 \\
\hline $\mathrm{KH}_{2} \mathrm{PO}_{4}$ & 0.334075 & 0.223789 & 1.49281 & 0.1738 & 82.62 & 2 \\
\hline $\mathrm{MgSO}_{4}$ & -0.166757 & 0.213748 & -0.780157 & 0.4578 & 54.22 & 8 \\
\hline $\mathrm{NaCl}$ & -0.255913 & 0.199887 & -1.28029 & 0.2363 & 76.37 & 4 \\
\hline $\mathrm{NaNO}_{3}$ & 0.235113 & 0.220942 & 1.06414 & 0.3183 & 68.17 & 6 \\
\hline $\mathrm{pH}$ & 0.182171 & 0.205343 & 0.887151 & 0.4009 & 59.91 & 7 \\
\hline Shaking rate & -0.281703 & 0.199093 & -1.41493 & 0.1948 & 80.52 & 3 \\
\hline Sucrose & 0.707217 & 0.211565 & 3.3428 & 0.0102 & 98.98 & 1 \\
\hline Temperature & 0.202723 & 0.183497 & 1.10477 & 0.3014 & 70 & 5 \\
\hline
\end{tabular}

Coefficient - coefficient of variance, $\mathrm{SE}$ - standard error, $t$-value - student $t$-test, $P$-value - corresponding level of significance, CL [\%] - confidence level [\%]

Table 5. ANOVA of the Plackett-Burman Model

\begin{tabular}{l|c|c|c|c|c}
\hline \multicolumn{1}{c|}{ Source } & SS & Df & MSS & F & $P$-value \\
\hline Model & 19.7964 & 9 & 2.1996 & 3.96 & 0.0328 \\
\hline Residual & 4.44637 & 8 & 0.555796 & & \\
\hline Total & 24.2428 & 17 & & & \\
\hline
\end{tabular}

$R^{2}-81.659$; percent and standard error - 0.745518; Df - degree of freedom; SS - sum of squares; ASS - adjusted sum of squares; MSS - mean sum of squares; F - Fisher function; $P$ - corresponding level of significance 
A

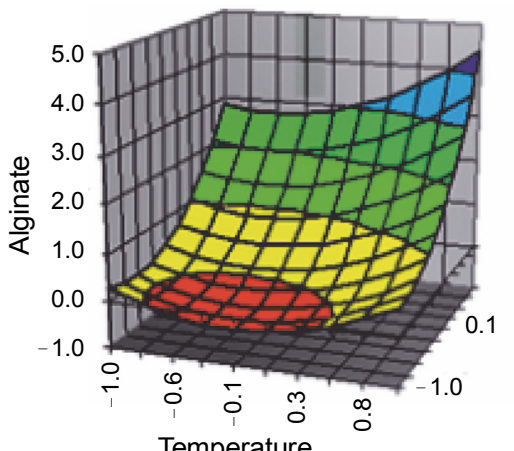

C

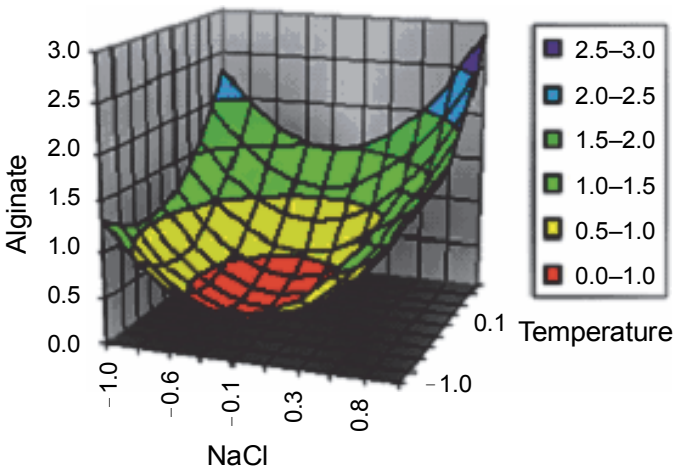

B

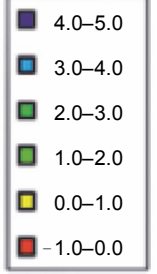

Sucrose

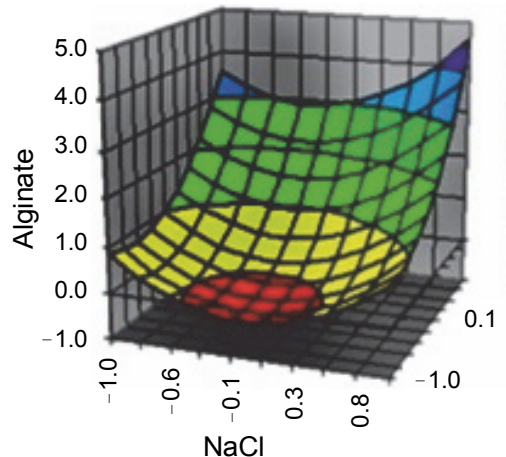

Sucrose

Fig. 2. A) Response surface plot showing the effects of sucrose and temperature, B) sucrose and $\mathrm{NaCl}$, and $\mathrm{C}$ ) temperature and $\mathrm{NaCl}$ on the rate of alginate production by $A$. vinelandii

A

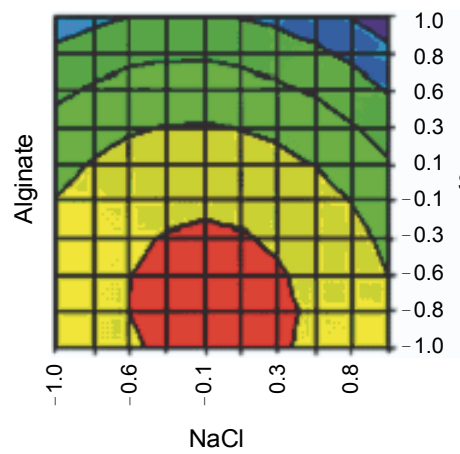

C

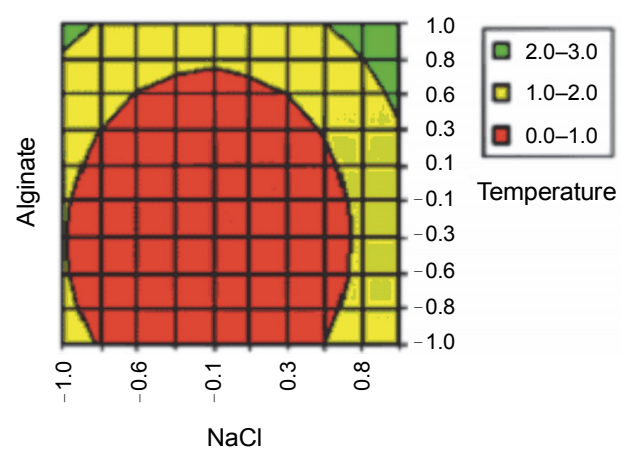

B

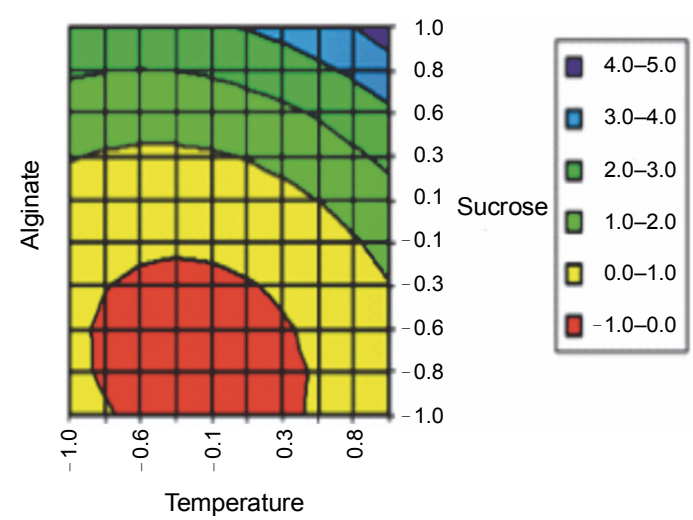

Fig. 3. A) Contour plot showing the effects of sucrose and temperature, $\mathrm{B}$ ) sucrose and $\mathrm{NaCl}$ and $\mathrm{C}$ ) temperature and $\mathrm{NaCl}$ on the rate of production of alginate by $A$. vinelandii 


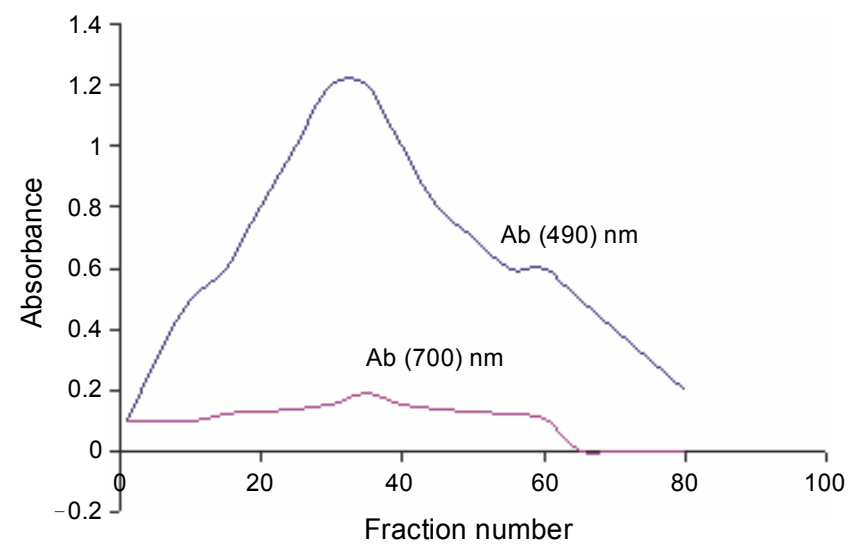

Fig. 4. Purification of alginate produced by $A$. vinelandii using gel chromatography; Ab (490) $\mathrm{nm}$ represents total carbohydrates and $\mathrm{Ab}(700) \mathrm{nm}$ represents the protein content of the sample

A

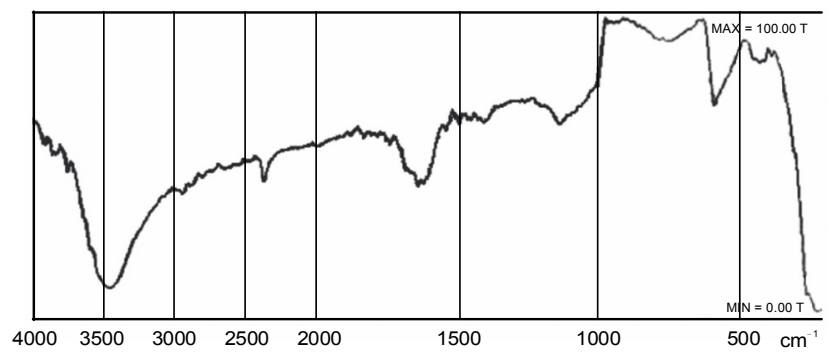

B

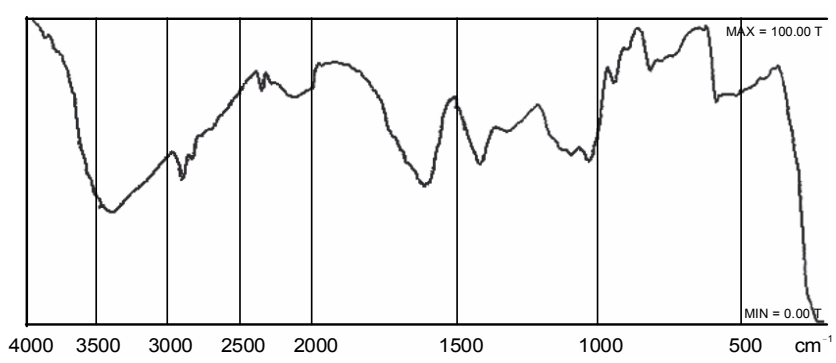

Fig. 5. A) IR analysis of purified alginate sample from $A$. vinelandii and B) standard algal alginate sample

by Bitter and Muir (1962). The protein content of the alginate samples was determined spectrophotometrically according to the method by Lowry and coworkers (1951). One milligram of pure dried alginate was used for an infrared (IR) analysis using a Perkin-Elmer 1430 spectrophotometer, following the method described by Sherbroochk-Cox and coworkers (1984). The IR spectrum of the isolated and purified alginates was compared with a known alginate sample.

\section{Results and discussion}

Alginates are biopolymers produced by brown algae and a few bacterial species (Sabra et al., 2001). Azoto- bactersp. and Pseudomonas aeruginosa are able to produce significant amounts of alginates (Clementi, 1997; Remminghorst and Rehm, 2006). In contrast to P. aeruginosa, $A$. vinelandii is a nonpathogenic bacterium that has been used for the development of a biotechnological process to produce alginates (Clementi, 1997; Sabra et al., 2001; Amara et al., 2006; Hussain and Amara, 2006). In this study, in the initial experiments (presented in Table 1), of the 30 local Egyptian Azotobacter strains isolated and screened out, five isolates produced alginate with variable amounts. Az5 isolate $(A$. vinelandii), among other alginate producers, was selected and subjected for further studies to improve alginate production levels and its characteristics. Alginates have a wide range of applications and are used as thickeners, stabilizers, gelling agents, and emulsifiers in the food, as well as in textile and pharmaceutical industries. Recent biotechnological advances show a promising potential application of alginates in the making of medical drugs (Yao et al., 2009; Lee and Mooney, 2012; Rinaudo, 2014).

Strategies for the biotechnological production of high-quality and/or tailor-made bacterial alginates are being developed by evaluation the influences of different nutritional and operational conditions (Sabra et al., 2001; Trujillo-Roldan et al., 2004; Diaz-Barrera and Soto, 2010; Diaz-Barrera et al., 2011; Auhim and Hassan, 2013). A response surface methodology (RSM) is a well-known method applied in the optimization of medium constituents and other critical variables responsible for the production of biomolecules (Montgomery, 1997). An experimental design is a common practice in biotechnology (Kalil et al., 2000), whereas optimization by changing one factor at a time is a time-consuming process as reported by various researchers, for example, Lakshman and coworkers (2004). Experimental design is an organized approach that yields more reliable information per experiment than unplanned approaches (Nickel et al., 2005). A number of statistical experimental designs have been used for optimizing different fermentation variables (Xu et al., 2002; Rao et al., 2004). The Plackett-Burman design (Plackett and Box, 1946) is a well-established and widely used statistical technique for screening and selection of critical culture variables (Rao, 2004; Kaur and Satyanarayana, 2005). The Plackett-Burman experimental design method was implemented using +1 and -1 for each variable as shown in Table 2 . Eighteen experiments were conducted and the results have been summarized 
Table 6. Box-Behnken design for optimized production of alginate by $A$. vinelandii

\begin{tabular}{c|c|c|c|c}
\hline $\begin{array}{c}\text { Experiment } \\
\text { No. }\end{array}$ & $\begin{array}{c}\text { Sucrose } \\
X_{1}\end{array}$ & $\begin{array}{c}\text { Temperature } \\
X_{2}\end{array}$ & $\begin{array}{c}\mathrm{NaCl} \\
X_{3}\end{array}$ & $\begin{array}{c}\text { Alginate } \\
\text { [g/l/day }]\end{array}$ \\
\hline 1 & $-1(5)$ & $-1(30)$ & $0(0.25)$ & 0.53 \\
\hline 2 & $1(30)$ & $-1(30)$ & $0(0.25)$ & 2.7 \\
\hline 3 & $-1(5)$ & $1(37)$ & $0(0.25)$ & 0.75 \\
\hline 4 & $1(30)$ & $1(37)$ & $0(0.25)$ & 4.19 \\
\hline 5 & $-1(5)$ & $0(33.5)$ & $-1(0)$ & 0.49 \\
\hline 6 & $1(30)$ & $0(33.5)$ & $-1(0)$ & 3.564 \\
\hline 7 & $-1(5)$ & $0(33.5)$ & $1(0.5)$ & 0.87 \\
\hline 8 & $1(30)$ & $0(33.5)$ & $1(0.5)$ & 4.94 \\
\hline 9 & $0(17.5)$ & $-1(30)$ & $-1(0)$ & 1.4 \\
\hline 10 & $0(17.5)$ & $-1(30)$ & $1(0.5)$ & 1.7 \\
\hline 11 & $0(17.5)$ & $1(37)$ & $-1(0)$ & 2.51 \\
\hline 12 & $0(17.5)$ & $1(37)$ & $1(0.5)$ & 2.78 \\
\hline 13 & $0(17.5)$ & $0(33.5)$ & $0(0.25)$ & 0.37 \\
\hline 14 & $0(17.5)$ & $0(33.5)$ & $0(0.25)$ & 0.07 \\
\hline 15 & $0(17.5)$ & $0(33.5)$ & $0(0.25)$ & 0.5 \\
\hline
\end{tabular}

$Y=\beta_{0}+\beta_{1} X_{1}+\beta_{2} X_{2}+\beta_{3} X_{3}+\beta_{12} X_{1} X_{2}+\beta_{13} X_{1} X_{3}+\beta_{23} X_{2} X_{3}+\beta_{11} X_{12}+\beta_{22} X_{22}$ $+\beta_{33} X_{33} ; X_{2}$ and $X_{3}$ are independent variables; $\beta_{1}, \beta_{2}$, and $\beta_{3}$ are linear coefficients; $\beta_{12}, \beta_{13}$, and $\beta_{23}$ are cross-product coefficients; and $\beta_{11}, \beta_{22}$, and $\beta_{33}$ are the quadratic coefficients

Table 7. Multiple regression results of the Box-Behnken design

\begin{tabular}{l|c|c|c|c|c|c}
\hline \multicolumn{1}{c|}{ Variables } & Coefficient & $\mathrm{SE}$ & $t$-value & $P$-value & $\mathrm{CL}[\%]$ & Rank \\
\hline Intercept & 0.313333 & 0.199338 & 1.57187 & 0.1768 & & \\
\hline Sucrose & 1.59425 & 0.122069 & 13.0602 & 0.0000 & 100 & 1 \\
\hline Sucrose* Sucrose & 1.04883 & 0.179681 & 5.8372 & 0.0021 & 99.79 & 3 \\
\hline Sucrose* Temperature & 0.3175 & 0.172632 & 1.83917 & 0.1253 & 87.47 & 6 \\
\hline Sucrose $^{*} \mathrm{NaCl}$ & 0.249 & 0.172632 & 1.44238 & 0.2088 & 79.12 & 7 \\
\hline Temperature & 0.4875 & 0.122069 & 3.99364 & 0.0104 & 98.96 & 3 \\
\hline Temperature* Temperature & 0.680333 & 0.179681 & 3.78634 & 0.0128 & 98.72 & 4 \\
\hline Temperature* $\mathrm{NaCl}$ & -0.0075 & 0.172632 & -0.043445 & 0.9670 & 3.3 & 8 \\
\hline $\mathrm{NaCl}^{*}$ & 0.29075 & 0.122069 & 2.38185 & 0.0630 & 93.7 & 5 \\
\hline $\mathrm{NaCl}^{*} \mathrm{NaCl}$ & 1.10383 & 0.179681 & 6.14329 & 0.0017 & 99.83 & 2 \\
\hline
\end{tabular}

Coefficient - coefficient of variance; SE - standard error; $t$-value - student $t$-test; $P$-value - corresponding level of significance, CL [\%] - confidence level [\%]

in Table 1 as an alginate production rate (g/l/day). The variations in the results showed the importance of utilizing an experimental design in nutritional condition optimization to map the points that affect the alginate production rates. The main effect of each variable was calculated and summarized in Figure 1 and Table 3. Positive values mean that such variables needed to be increased and the negative ones that they needed to be lowered. A temperature of $37^{\circ} \mathrm{C}, \mathrm{pH}$ of 7 , sucrose at 30 $\mathrm{g} / 1, \mathrm{NaNO}_{3}$ at $2 \mathrm{~g} / \mathrm{l}$, and $\mathrm{KH}_{2} \mathrm{PO}_{4}$ at $1 \mathrm{~g} / 1$ and $0.5 \mathrm{~g} / 1$ 
Table 8. ANOVA statistical analysis of variance of the Box-Behnken Model

\begin{tabular}{l|c|c|c|c|c}
\hline & Df & SS & MSS & F & $P$-value \\
\hline Model & 9 & 32.54723 & 3.616359 & 30.33676 & 0.000772 \\
\hline Residual & 5 & 0.596036 & 0.119207 & & \\
\hline Total & 14 & 33.14326 & & & \\
\hline
\end{tabular}

$R^{2}-98.2016$; percent and standard error $=0.345264$; $D f-$ degree of freedom; $\mathrm{SS}$ - sum of squares; MSS - mean sum of squares; F - Fisher function; $P$-value corresponding level of significance

Table 9. Final optimization of alginate production by $A$. vinelandii using Excel solver

\begin{tabular}{l|c|c}
\hline \multicolumn{1}{c|}{ Media content } & $\begin{array}{c}\text { Distilled water* } \\
{[\mathrm{g} / \mathrm{l}]}\end{array}$ & $\begin{array}{c}\text { Distilled water } \\
{[\mathrm{g} / \mathrm{l}]}\end{array}$ \\
\hline Sucrose & 30.00 & 30.000 \\
\hline $\mathrm{NaCl}$ & 0.50 & 0.500 \\
\hline $\mathrm{CaCl}_{2}$ & 0.06 & 0.060 \\
\hline $\mathrm{NaNO}_{3}$ & 0.10 & 0.100 \\
\hline $\mathrm{KH}_{2} \mathrm{PO}_{4}$ & 1.00 & 1.000 \\
\hline $\mathrm{MgSO}_{4}$ & 0.00 & 0.010 \\
\hline $\mathrm{FeSO}_{4}$ & 0.00 & 0.010 \\
\hline NaMoO & 0.001 \\
\hline Alginate [g/l/day] & 5.40 & 8.500 \\
\hline Model accuracy & 88.84 & 140.000 \\
\hline
\end{tabular}

* the experiment followed the Excel solver optimization for the $Y$ value derived from the Box-Behnken method; $\wedge$ the experiment followed the Excel solver optimization for the $Y$ value derived from Box-Behnken, but variables with $0 \mathrm{~g} / \mathrm{l}$ amounts changed

positively affected the alginate production rate, while no addition of $\mathrm{NaCl}$ nor $\mathrm{MgSO}_{4}$ and a shaking rate of $200 \mathrm{rpm}$ showed negative effects (Fig. 1 and Table 3), which is in contrast to the results obtained by Diaz-Barrera and coworkers (2011), in continuous cultures. The nine variables analyzed using the linear multiple regression analysis method aimed at producing a fitted model. The coefficient level of the variance in the conducted model was calculated from the $P$-value (Table 2). The analysis of variance using the ANOVA method (Table 5) resulted in a $P$-value of 0.0328 , significant at the $95 \%$ confidence level. The First-order model was alginate production rate $(Y)$ $=1.46111+0.0259903 \cdot \mathrm{FeSO}_{4}+0.334075 \cdot \mathrm{KH}_{2} \mathrm{PO}_{4}$ $-0.166757 \cdot \mathrm{MgSO}_{4}-0.255913 \cdot \mathrm{NaCl}+0.235113$ $\cdot \mathrm{NaNO}_{3}+0.182171 \cdot \mathrm{pH}-0.281703 \cdot$ Shaking rate $+0.707217 \cdot$ Sucrose $+0.202723 \cdot$ Temperature. The $R^{2}$ statistics indicated that the model fitted and explained $81.659 \%$ of the variability in the alginate production rate.
The adjusted $\mathrm{R}^{2}$ statistics, which is more suitable for comparing models with different numbers of independent variables, was $61.0253 \%$. The estimates showed that the standard error of the residual was 0.745518 . Based on $t$ statistics, $P$-value, and the confidence level percentage from the Plackett-Burman design (Table 4 and Table 5) as well as the results from our previous study on poly- $\beta$-hydroxybutyrate (PHB) optimization, using the same strategy (El-Shanshoury et al., 2013), we conlcluded that the Plackett-Burman design is a promising tool to improve alginate production. $\mathrm{KH}_{2} \mathrm{PO}_{4}$ at $2 \mathrm{~g} / \mathrm{l}$ and a shaking rate of $225 \mathrm{rpm}$ should not be used because they promote the PHB production, which in turn interferes with the alginate production rate, which is in accordance with the results obtained by Pena and coworkers (1997), and Mejia and coworkers (2010). Because sucrose and $\mathrm{NaCl}$ concentrations, as well as temperature, significantly influenced alginate production, 
they were selected for further optimization. Other variables did not significantly influence alginate production, hence they were used in the amounts as in the Plackett-Burman experiment number 13, which exhibited the maximum alginate production rate. Using the Box-Behnken method, 18 experiments were designed and different alginate production rates were determined (summarized in Table 4). An analysis of variance using the ANOVA test resulted in a $P$-value of 0.000772 , which showed a highly significant relationship between the variables, at $99 \%$ confidence level (Table 8 ). The $\mathrm{R}^{2}$ statistical analysis indicated that the fitted model explained $98.2016 \%$ of the variance. The multiple linear regression models of the Box-Behnken analysis experiments described the relationship between the alginate production rate and three independent variables: sucrose $\left(X_{1}\right)$, temperature $\left(X_{2}\right)$, and $\mathrm{NaCl}\left(X_{3}\right)$ as indicated in Table 6 . The equation of the fitted model was: alginate production rate $[Y]=0.313333+1.59425 \cdot$ sucrose +1.04883 - sucrose $\cdot$ sucrose $+0.3175 \cdot$ sucrose $\cdot$ temperatures $+0.249 \cdot$ sucrose $\cdot \mathrm{NaCl}+0.4875 \cdot$ temperatures $+0.680333 \cdot$ temperatures $\cdot$ temperature -0.0075 - temperature $\cdot \mathrm{NaCl}+0.29075 \cdot \mathrm{NaCl}+1.10383 \cdot \mathrm{NaCl}$ - $\mathrm{NaCl}$. The $P$-value of the independent variables was 0.9670 , but calculated for temperature $\cdot \mathrm{NaCl}$ was greater or equal to 0.10 , which was not statistically significant at the $90 \%$ or higher confidence level. From the statistical analysis, the sucrose concentration has the most significant effect on the alginate production rate, where it showed the $P$-value equal to 0.0102 and the highest confidence level percentage, which is in contrast to the results obtained by Mejia and coworkers (2010) in a two-stage fermentation process for alginate production. This was clear from the analysis of the Box-Behnken design, where the confidence level percentage of sucrose equaled $100 \%$ of the P-value from the ANOVA test, which was $P=0.000772$; the $\mathrm{R}^{2}$ indicated that the model fitted explained $98.20 \%$ of the variance. The highest significant value as well as the highest confidence level percentage in both the Plackett-Burman and the Box-Behnken experiments were obtained from sucrose. These results are in agreement with most of the previous studies and prove the power of experimental design in mapping the effective points on the optimization.

The response surface and counter-plots of each of the two optimized variables, their interaction, and effect on alginate production have been shown in Figures 2 and 3 .
The highest level of the three variables, as obtained from the maximum point of the polynomial model, was further optimized using the solver function of Microsoft Excel tools and was found for sucrose $\left[X_{1}\right]=30 \mathrm{~g} / 1$, temperature $\left[X_{2}\right]=37^{\circ} \mathrm{C}$, and $\mathrm{NaCl}\left[X_{3}\right]=0.5 \mathrm{~g} / 1$ with a calculated prediction of the alginate production rate equal to 6.077833 $[Y]$. The flask experiment was conducted, and $Y$ value was $5.4 \mathrm{~g} / \mathrm{l} /$ day with model accuracy equal to $88.84 \%$. The culture medium was supplemented with different minerals at different concentrations. By adding $0.01 \mathrm{~g} / 1 \mathrm{MgSO}_{4}$, $0.01 \mathrm{~g} / \mathrm{FSO}_{4}$, and $0.001 \mathrm{~g} / \mathrm{N} \mathrm{NaMoO}_{4}$ to the culture medium, the alginate production rate was found to improve up to $8.5 \mathrm{~g} / \mathrm{l} /$ day (model accuracy $140 \%$ ) as shown in Table 8 . These nutrients, in addition to sucrose, were possibly responsible for the increase in the alginate production rate as suggested by Mejia and coworkers (2010). However, the overall results obtained in this study confirmed that the experimental design methodology used herein is a suitable method for the optimization of alginate production by $A$. vinelandii, amounting up to $8.5 \mathrm{~g} / \mathrm{l} /$ day. However, using Pholiota squarrosa, after the optimization of medium components using a response surface methodology, an extracellular alginate production $0.876 .32 \mathrm{~g} / \mathrm{l}$ of cultivation medium has been reported by Wang and $\mathrm{Lu}$ (2004). Morover, it is possible to engineer $A$. vinelandii strains possessing increased levels of transcription from the $\operatorname{alg} D$ operon, and thus increasing the levels of alginate production. Indeed, when this was combined with the disruption of the polyhydroxybutyrate pathway (thus allowing more carbon sources for alginate biosynthesis) up to $7 \mathrm{~g} / \mathrm{l}$ of alginate was obtained (Pena et al., 2002; Calindo et al., 2007). Furthermore, a disruption of the $\mathrm{Na}^{+}$-translocating NADH: ubiquinone oxidoreductase complex in $A$. vinelandii lead to an alginate overproducing phenotype; this alginate also had a higher degree of acetylation and a lower $\mathrm{G} / \mathrm{M}$ ratio, though the exact mechanism remains unclear $(\mathrm{Nu}-$ nez et al., 2009; Gaytanet al., 2012).

The isolated and purified alginate samples were analyzed for total carbohydrates and total protein contents and were found to be 490 and $700 \mathrm{~nm}$, respectively. The fractions showed a low protein level $(300 \mu \mathrm{g} / \mathrm{ml})$ and high alginate contents (Fig. 4). The alginates were reprecipitated and lyophilized for further analysis. The purified alginate samples were compared with a known A0682 alginic acid sodium salt from brown algae using the IR spectrophotometer, and the peaks of the alginate 
were nearly the same as those of the reference sample, which indicated a high purity of the alginate (Fig. 5).

\section{Conclusions}

The analysis of 30 Azotobacter strains isolated from Egyptian soils showed the best growth on a nitrogen-free medium. Five best nitrogen fixing isolates were investigated for their ability to produce alginates. The alginate production rates obtained in the 18 experiments conducted, proved the importance of the Plackett-Burman design in mapping the performance of each variable during the alginate production process. The ranking of the variables regarding their levels of significance showed that sucrose was the most significant variable followed by $\mathrm{KH}_{2} \mathrm{PO}_{4}$, shaking rate, $\mathrm{NaCl}$, and temperature. Using the Plackett-Burman and Box-Behnken methods/ designs, the Excel solver, and a statistical and logical selection of the variables, we were able to improve the rate of alginate production by $A$. vinelandii. Strategies used in this study are recommended in optimizing the production of bioproducts, especially those controlled by complicated enzymatic systems. An advancement in the regulation of alginate biosynthesis in bacteria and introducing mutation into genes encoding enzymes involved in alginate biosynthesis enable the production of alginates with tailor-made features and a wide range of applications. Understanding the mechanisms of epimerization, acetylation, and degradation, as well as their regulation in $A$. vinelandii is crucial for obtaining high-quality products required by new markets. Because many $A$. vinelandii strains are regarded as secure, the utilization of alginate delivered from an ecofriendly Azotobacter strain, as used in this study, could bring an added value to alginates used for technical and medical applications.

\section{References}

Abdel-Fattah Y.R., Olama Z.A. (2002) L-asparaginase production by Pseudomonas aeruginosa in solid-state culture: evaluation and optimization of culture conditions using factorial designs. Process Biotechnol. 38: 115-122.

Amara A.A., Hussein Z.H. (2006) Offline controlling of Pseudomonas aeruginosa resistant to protein inhibitor antibiotics using combination of EDTA and Na-citrate or disinfectants. Microbiol. China 33: 95-100.

Auhim H.S., Hassan S.S. (2013) Production and characterization of alginate from Azotobacter vinellandii A3. IJAPBC 2: 507-5012.
Bitter T., Muir H.M. (1962) A modified uronic acid carbazole reaction. Analyt. Biochem. 4: 330-334.

Box G.E.P., Behnken D.W. (1960) Some new three level designs for the study of quantitative variables. Technomet. 2: 455-457.

Charles T., Othman Z., Wan A., Wan M., Mohamed R.S., Ramlan A., El Enshasy H.A. (2012) Production of Alginate by Azotobacter vinellandii in semi-industrial scale using batch andfed-batch cultivation systems. J. Adv. Sci. Res. 3: 45-50.

Chen W.P., Chen J.Y., Chang S.C., Su C.L. (1985) Bacterial alginate produced by a mutant of Azotobacter vinelandii. Appl. Environ. Microbiol. 49: 543-546.

Clementi F. (1997) Alginate production by Azotobacter vinelandii. Critic. Rev. Biotechnol. 17: 327-361.

Cote G.L., Krull L.H. (1988) Characterization of the exocellular polysaccharides from Azotobacter chroococcum. Carbohyd. Res. 181: 143-152.

Crescenzi V. (1995) Microbial polysaccharides of applied interest. Ongoing research activities in Europe. Biotechnol. Progr. 11: 251-259.

Diaz-Barrera A., Soto E. (2010) Biotechnological uses of Azotobacter vinelandi: Current state, limits, and prospects. Afr. J. Biotechnol. 9: 5240-5250.

Diaz-Barrera A., Aguirre A., Berrios J., Acevedo F. (2011) Continuous cultures for alginate production by Azotobacter vinelandii growing at different oxygen uptake rates. Proc. Biochem. 46: 1879-1883.

El-Shanshoury A.R., Kenawy R., Amara A.A., Salama A.F., Kishk Sh.S. (2013) Optimization of polyhydroxybutyrate (PHB) production by Azotobacter vinelandii using experimental design. Int. J. Curr. Microbiol. App. Sci. 2: 227-241.

Gacesa P. (1998) Bacterial alginate biosynthesis - recent progress and future prospects. Microbiol. 144: 1133-1143.

Galal G.F., Ouda S.M. (2014) Production of Alginate by different isolates of Azotobacter species. Life Sci. J. 11: 29-38.

Galindo E., Pena C., Nunez C., Segura D., Espin G. (2007) Molecular and bioengineering strategies to improvealginate and polyhydroxyalkanoate production by Azotobacter vinelandii. Microbiol. Cell Fact. 7: 1-16.

Gaytan I., Pena C., Nunez C., Cordova M.S., Espin G., Galindo E. (2012) Azotobacter vinelandii lacking the $N a(+)-N Q R$ activity: a potential source for producing alginates with improved properties and at high yield. World J. Microbiol. Biotechnol. 28: 2731-2740.

Grasdalen H. (1983) High field, 1 H-N.M.R. spectroscopy of alginate: sequential structure and linkage conformations. Carbohydr. Res. 118: 255-260.

Hussain Z.M., Amara A.A. (2006) A case-by-case study using antibiotic-EDTA combination to control Pseudomonas aeruginosa. Pakist J. Pharm. Sci. 193: 236-243.

Kalil S.J., Maugeri F., Rodrigues M.I. (2000) Response surface analysis and simulation as a tool for bioprocess design and optimization. Process Biochem. 35: 539-550. 
Kaur P., Satyanarayana T. (2005) Production of cell-bound phytase by Pichia anomaly in an economical cane molasses medium: optimization using statistical tools. Process. Biochem. 40: 3095-3102.

Lakshman K., Rastogi N.K., Shamala T.R. (2004) Simultaneous and comparative assessment of parent and mutant strain of Rhizobium meliloti for nutrient limitation and enhanced polyhydroxyalkanoate PHA production using optimization studies. Process. Biochem. 39: 1977-1983.

Lee K.Y., Mooney D.J. (2012) Alginate: properties and biomedical applications. Prog. Polym. Sci. 37: 106-126.

Lowry O.H, Rosebrough N.J, Garr A.L., Randall R.J. (1951) Protein measurement with the folin phenol reagent. J. Biol. Chem. 139: 265-275.

Mazumder A., Holdt S.L., De Francisci D., Alvarado-Morales M., Mishra H.N., Angelidaki I. (2016) Extraction of alginate from Sargassum muticum: process optimization and study of its functional activities. J. Appl. Phycol. 28: 3625-3634.

Mejia M.A., Segura D., Epsin G., Galindo E., Pena C. (2010) Two-stage fermentation process for alginate production by Azotobacter vinelandii mutant altered in poly- $\beta$-hydroxybutyrate (PHB) synthesis. J. Appl. Microbiol. 108: 55-61.

Montgomery D.C. (1997) Response surface methods and other approaches to process optimization. [In:] Design and analysis of experiments. Ed. Montgomery D.C., New York: John Wiley and Sons: 427-510.

Nickel P.I., Pettinari M.J., Méndez B.S., Galvagno M.A. (2005) Statistical optimization of a culture medium for biomass and poly 3-hydroxybutyrate production by a recombinant Escherichia coli strain using agro-industrial by-products. Internat. Microbiol. 8: 243-250.

Nunez C., Bogachev A.V., Guzman G., Tello I., Guzman J., Espin G. (2009) The Nat-translocating NADH: ubiquinone oxidoreductase of Azotobacter vinelandii negatively regulates alginate synthesis. Microbiol. 155: 249-256.

Pena C., Campos N., Galindo E. (1997) Changes in alginate molecular mass distribution, broth viscosity and morphology of Azotobacter vinelandii cultured in shake flasks. Appl. Microbiol. Biotechnol. 48: 510-515.

Pena C., Miranda L., Segura D., Nunez C., Espin G., Galindo E. (2002) Alginate production by Azotobacter vinelandii mutants altered in poly-beta-hydroxybutyrate and alginate biosynthesis. J. Ind. Microbiol. Biotechnol. 29: 209-213.

Pena C., Hernandez L., Galindo E. (2006) Manipulation of the acetylation degree of Azotobacter vinelandii alginate by supplementing the culture medium with 3-(N-morpholino) propane-sulfonic acid. Lett. Appl. Microbiol. 43: 200-204.

Plackett P., Burman J.P. (1946) The design of optimum multifactorial experiments. Biomet. 37: 305-325.

Rao R.S., Prakasham R.S., Prasad K.K., Rajesham S., Sarma P.N., Rao L.V. (2004) Xylitol production by Candida sp.: parameter optimization using Taguchi approach. Process. Biochem. 39: 951-956.

Rehm B., Valla S. (1997) Bacterial alginate: biosynthesis and application. Appl. Microbiol. Biotechnol. 48: 281-88.
Remminghorst U., Rehm B. (2006) Bacterial alginates: from biosynthesis to applications. Biotechnol. Lett. 28: 1701-1712.

Rinaudo M. (2014) Biomaterials based on a natural polysaccharide: alginate. TIP Rev. Especial. Cien. Quím.-Biol. 17: 92-96.

Sabra W. (1999) Microaerophilic production of alginate by Azotobacter vinelandii. TU Carolo-Wilhelmina zu Braunschweig, Alexandria, Egypt: 37-54.

Sabra W., Zeng A.P., Deckwer W.D. (2001) Bacterial alginate: physiology, product quality, and process aspects. Appl. Microbiol. Biotechnol. 56(3-4): 315-325.

Schmid T., Burkhard J., Yeo B.S., Zhang W., Zenobi R. (2008) Towards achemical analysis of nanostructures in biofilms I: Imaging of biological nanostructures. Anal. Bioanal. Chem. 391: 1907-1916.

Segura D., Cruz T., Espin G. (2003) Encystment and alkyl resorcinol production by Azotobacter vinelandii strains impaired in poly-beta-hydroxybutyrate synthesis. Arch. Microbiol. 179: 437-443.

Sherbrook-Cox V.S., Russel N., Jgacesa P. (1984) The purification and chemical characterization of the alginate present in the extracellular material produced by mucoid strains of Pseudomonas aeruginosa. Carbohyd. Res. 4: 284-291.

Steppan D.D., Werner J., Yeater R.P. (1998) Essential regression and experimental design for chemists and engineers (Software). www.geocitie.com/SiliconValley/Network/ 1032/CGPage1.html

Stowe R.A., Mayer R. P. (1966) Efficient screening of process variables. Ind. Eng. Chem. 58: 36-40.

Szekalska M., Puciłowska A., Szymańska E., Ciosek P., Winnicka K. (2016) Alginate: Current use and future perspectives in pharmaceutical and biomedical applications. Int. J. Polymer. Sci. 2016: 1-17.

Thielen P., Strathmann M., Jaeger K.E., Flemming H.C., Wingender J. (2005) Alginate acetylation influences initial surface colonization by mucoid Pseudomonas aeruginosa. Microbiol. Res. 160: 165-176.

Trujillo-Roldan M., Moreno S., Espin G., Galindo E. (2004) The roles of oxygen and alginatelyase in determining the molecular weight of alginate produced by Azotobacter vinelandii. Appl. Microbiol. Biotechnol. 63: 742-747.

Vancura V., Mancura J. (1960) Indole derivative in Azotobacter culture. Folia Microbiol. 5: 293-297.

Wang Y.X., Lu Z.X. (2004) Statistical optimization of media for extracellular polysaccharide by Pholiotas quarrosa Pers. Ex Fr. Quel. AS 5.245 under submerged cultivation. Biochem. Eng. J. 20: 39-47.

Xu C.P., Kim S.W., Hwang H.J., Yun J.W. (2002) Application of statistically based experimental designs for the optimization of exopolysaccharide production by Cordyceps military NG3. Biotechnol. Appl. Biochem. 36: 127-131.

Yao B., Ni C., Xiong Ch., Zhu Ch., Bo Ch. (2009) Huang: Hydrophobicmodification of sodium alginate and its application in a drug controlled release. Biopro. Biosyst. Eng. 33: 457-463. 